\title{
Penerapan Rute Aman Selamat Sekolah di Kawasan Pendidikan Kota Balikpapan
}

\author{
Budiharso Hidayat, Ananta Dwi Sambada, Fauzi \\ Politeknik Transportasi Darat Indonesia-STTD Bekasi \\ Email: budiharso.hidayat@ptdisttd.ac.id
}

\begin{abstract}
Tujuan penelitian ini adalah untuk menganalisis penerapan rute aman selamat sekolah di kawasan pendidikan kota Balikpapan. Penelitian ini menggunakan jenis penelitian kualitatif dengan pendekatan analisis deskriptif. Data dalam penelitian ini berjenis data primer dan data sekunder. Pada kajian ini peneliti mengambil populasi masing-masing dari 4 sekolah di kawasan pendidikan. Dalam mengambil sampel peneliti menggunakan rumus Slovin dengan tingkat kepercayaan 90\%. Berdasarkan hasil analisis, dapat disimpulkan bahwa 1) Kawasan Rute Aman Selamat Sekolah (RASS) mencakup 4 sekolah yaitu SD 001 Balikpapan, SMPN 12 Balikpapan, SMPN 1 Balikpapan, SMAN 1 Balikpapan; 2) Fasilitas rute pejalan kaki dan desainnya mencakup lebar trotoar pada jalan KP Tendean, jalan Wilyopuspoyudho, Jalam Arsh. Moh, Jalan Milino, Jalan Brigjen Ery Supardjan, Jalan Tanjung Pura, Jalan Telagasari, Jalan Telagasari Dalam, Jalan RE Martadinata. Adapun fasilitas penyebrangan terdapat pada Jalan KP Tendean; 3) Fasilitas angkutan umum mencakup mendesain halte untuk lokasi eksisting; dan 4) Fasilitas drop zone/pick up point diterapkan agar memberikan rasa aman bagi siswa yang diantar jemput dan tidak mengganggu aktivitas lau lintas sekitar.
\end{abstract}

Kata Kunci: Rute Aman Sekolah, Pendidikan, Penerapan.

\section{Abstract}

The purpose of this study was to analyze the application of safe school routes in the education area of Balikpapan city. This research uses qualitative research with descriptive analysis approach. The data in this study are primary data and secondary data. In this study, the researchers took the population of each of the 4 schools in the education area. In taking the sample the researcher used the Slovin formula with a $90 \%$ confidence level. Based on the results of the analysis, it can be concluded that 1) the Safe Safe Route for Schooling (RASS) includes 4 schools, namely Elementary Schol 001 Balikpapan, State Middle School 12 Balikpapan, State Middle School 1 Balikpapan, High School 1 Balikpapan; 2) The pedestrian route facilities and their designs include the width of the sidewalks on Jalan KP Tendean, Jalan Wilyopuspoyudho, Jalam Arsh. Moh, Milino Street, Brigadier General Ery Supardjan Street, Tanjung Pura Street, Telagasari Street, Telagasari Dalam Street, RE Martadinata Street. The crossing facilities are located on Jalan KP Tendean; 3) Public transportation facilities include designing shelters for existing locations; and 4) Drop zone/pick up point facilities are implemented 
in order to provide a sense of security for students who are picked up and picked up and do not interfere with surrounding traffic activities.

Keywords: School Safe Routes, Education, Application.

\section{A. PENDAHULUAN}

Pendidikan merupakan salah satu kebutuhan pokok bagi warga Negara Indonesia, dimana pendidikan merupakan suatu unsur untuk menyiapkan generasi penerus bangsa yang nantinya akan membangun negara Indonesia, maka dari itu sudah sepatutnya kita menciptakan rasa aman dan nyaman kepada para penerus bangsa dalam hal berlalu lintas (Aprizon, 2020).

Kota Balikpapan, merupakan pintu gerbang di provinsi Kalimantan Timur dengan Luas wilayah 503,30 Km2 yang meliputi enam kecamatan. Berdasarkan data dari Badan Pusat Statistik, jumlah penduduk kota Balikpapan tahun 2018 ada 645.727 jiwa (Kota Balikpapan Dalam Angka, 2018). Adapun dari enam kecamatan dimana meliputi kecamatan Balikpapan Barat, Balikpapan Timur, Balikpapan Selatan,Balikpapan Utara, Balikpapan Tengah, dan Balikpapan Kota. Balikpapan terdiri dari 34 Kelurahan yang tersebar di enam kecamatan. pada kecamatan Balikpapan Kota memiliki beberapa kawasan, antara lain kawasan perdagangan dan jasa, kawasan perkantoran, dan kawasan pendidikan. Kawasan pendidikan pada perkotaan Balikpapan ini terletak dekat pusat kota atau central bussiness district (CBD). Adapun sekolah sekolah tersebut yaitu SDN 001, SMPN 12, SMPN 1, dan SMAN 1 Balikpapan. Sekolah-sekolah tersebut berada di satu jalan yaitu jalan Kapten Piere Tendean tetapi berbeda tipe jalan. SDN 001 dan SMPN 12 terletak pada ruas jalan dengan tipe 2/2UD dan lebar 7 meter, sedangkan SMPN 1, dan SMAN 1 terletak pada ruas jalan dengan tipe 4/2D dan lebar jalan per jalur 7 meter.

Dari hasil survey traffic counting dapat disimpulkan bahwa tingginya penggunaan kendaraan pribadi pada saat jam berangkat dan pulang sekolah menyebabkan tingginya volume kendaraan pada kawasan tersebut dengan nilai v/c ratio yaitu 0,65 dan 0,73, kemudian dari hasil wawancara pelajar masih banyaknya siswa/I yang mengendarai sepeda motor tapi belum memiliki SIM (Arianto \& Heriwibowo, 2017). Hal ini membuat kawasan tersebut menjadi crowded ditambah dengan banyaknya kendaraan yang berhenti ataupun memarkirkan kendaraan di tepi jalan yang menyebabkan berkurangnya kapasitas jalan dan terjadi kemacetan.

Adapun masalah angkutan umum di kawasan tersebut yaitu masih rendahnya standar pelayanan angkutan umum, khususnya pada kawasan tersebut waktu menunggu yang lama dimana rata-rata siswa menunggu 15 sampai dengan 20 menit ketika ingin menggunakan angkutan ditambah dengan tidak adanya fasilitas angkutan umum di kawasan tersebut seperti halte .Maka dari itu banyak masyarakat memilih angkutan pribadi (Liliany, et al.,2019). Hal ini mempengaruhi rasa nyaman masyarakat terutama anak-anak dalam berkegiatan berjalan kaki dan bersepeda. Kawasan pendidikan yang terdiri dari 6 sekolah tersebut berjumlah 4.674 siswa, dimana fasilitas penunjang keselamatan untuk pejalan kaki, pesepeda dan rambu-rambu keselamatan belum memadai serta terdapat banyak pelajar yang berjalan kaki dan bersepeda menuju sekolah maka dikhawatirkan tingginya resiko pelajar terkena kecelakaan (Dedi, 2020). Apalagi karakteristik pelajar yang menyebrang jalan sembarangan yang dapat membahayakan pelajar sendiri. 
Dari data kecelakaan di Kota Balikpapan dari tahun 2016 sampai dengan 2018 terdapat 521 korban kecelakaan. Pelajar merupakan korban dengan angka terbanyak setelah karyawan swasta dalam kasus kecelakaan lalu lintas. Adapun waktu kecelakaan tertinggi yaitu pada pukul 06.0012.00 dengan 87 kejadian menjelaskan bahwa tingkat kecelakaan terjadi pada waktu jam sekolah. Itu merupakan bukti bahwa pelajar sangat rentan dengan kecelakaan lalu lintas. Apalagi di kawasan pendidikan tersebut dari hasil wawancara kepada masyarakat sekitar sering terjadi kecelakaan, walaupun tergolong kecelakaan ringan, hal ini sangat mengancam keselamatan dari para siswa siswi di kawasan tersebut, didukung dengan data sat lantas terdapat 18 kejadian kecelakaan di daerah tersebut, walau tidak menimbulkan korban jiwa tetap saja hal ini sangat berbahaya untuk keselmatan siswa/I di lokasi tersebut (Hartono et al.,2020).

Pada PM nomor 16 tahun 2016 sudah diterangkan bahwa dalam mewujudkan kepedulian atas lokasi sekolah yang kurang ramah untuk diakses pelajar dengan berjalan kaki dan bersepeda serta angkutan umum, maka mendorong inisiatif untuk menyediakan kawasan yang aman dan selamat di lingkungan sekolah dengan Penerapan Rute Aman Selamat Sekolah (RASS) (Mushoffan \& Harjoto, 2019). Program Rute Aman Selamat Sekolah (RASS) bertujuan untuk mengurangi kecelakaan lalu lintas yang melibatkan pelajar, program RASS adalah program untuk mendorong murid dan orang tua murid untuk lebih memilih berjalan kaki, bersepeda, atau menggunakan angkutan umum sebagai pilihan yang selamat, aman, nyaman, dan menyenangkan, untuk berangkat dan pulang sekolah, daripada menggunakan sepeda motor yang rawan kecelakaan (Haradongan, 2017). Selain itu, program ini diharapkan dapat mengurangi tindak kejahatan dan kekekerasan terhadap pelajar, mengurangi konsumsi bahan bakar serta menjaga kesehatan, memberikan manfaat secara tidak langsung untuk mengurai kemacetan, dan dampak lanjutannya dapat menumbuhkan kesadaran atas pentingnya berperilaku tertib agar selamat di jalan bagi masyarakat dan di sekitar sekolah (Ulandari \& Pangaribuan, 2015).

\section{B. STUDI LITERATUR}

\section{Keselamatan}

Keselamatan berasal dari kata dasar selamat. Menurut Kamus Besar Bahasa Indonesia selamat adalah terhindar dari bencana, aman sentosa, sejahtera, tidak kurang suatu apapun, sehat, tidak mendapat gangguan, kerusakan, beruntung, tercapai maksudnya, tidak gagal. Namun arti selamat dapat juga suatu keadaan yang aman serta terhindar dan terlindungi secara fisik, sosial, spiritual, finansial, politik, emosional, pekerjaan, psikologi, pendidikan atau berbagai konsekuensi lain dari kegagalan, kerusakan, kesalahan, kecelakaan, kerugian, atau berbagai kejadian lain yang tidak diinginkan (Heriwibowo, 2020). Keselamatan jalan raya adalah suatu upaya mengurangi kecelakaan jalan yang dapat disebabkan oleh prasarana, faktor sekeliling, sarana, manusia, rambu atau peraturan (Prasetyo et al.,2020).

Keselamatan jalan raya merupakan suatu bagian yang tak terpisahkan dari konsep tranportasi berkelanjutan yang menekankan pada prinsip transportasi yang aman, nyaman, cepat, bersih (mengurangi polusi/pencemaran udara) dan dapat diakses oleh semua orang dan kalangan, baik oleh para penyandang cacat, anak- anak, ibu-ibu maupun para lanjut usia. Anak-anak memiliki 
hak untuk mendapatkan perlindungan dari kekerasan dan kecelakaan yang menimbulkan perlakuan/cedera dan kematian (Nurcahyo \& Iskandaria, 2020). Negara melalui Undang-Undang Dasar Republik Indonesia 1945 pasal 28B ayat (2) menyatakan "Setiap anak berhak atas kelangsungan hidup, tumbuh dan berkembang serta berhak atas perlindungan dari kekerasan dan diskriminasi”, UU No 35 Tahun 2014 tentang perlindungan anak.

Keamanan Lalu Lintas dan Angkutan Jalan adalah suatu keadaan terbebasnya setiap orang, barang, dan/atau kendaraan dari gangguan perbuatan melawan hukum, dan/atau rasa takut dalam berlalu lintas (Undang-Undang Nomor 22 tahun 2009 tentang LLAJ pasal 1 angka 30). Keselamatan Lalu Lintas dan Angkutan Jalan adalah suatu keadaan terhindarnya setiap orang dari resiko kecelakaan selama berlalu lintas yang disebabkan oleh manusia, kendaraan, jalan, dan/atau lingkungan. (Undang-Undang Nomor 222009 tentang LLAJ pasal 1 angka 31)

Tujuan dari keselamatan jalan raya adalah untuk menekan angka kecelakaan lalu lintas di Indonesia. Hal ini karena dengan rendahnya angka kecelakaan lalu lintas maka kesejahteraan dan keselamatan bagi mereka di jalan raya semakin terjamin. Sedangkan fungsi keselamatan jalan raya adalah untuk menciptakan ketertiban lalu lintas agar setiap orang yang melakukan kegiatan atau aktivitas di jalan raya dapat berjalan dengan aman.

Dalam Undang-Undang Nomor 22 Tahun 2009 tentang LLAJ dijelaskan bahwa setiap jalan yang digunakan untuk Lalu Lintas umum wajib dilengkapi dengan perlengkapan jalan berupa: a) Rambu lalu lintas; b) Marka jalan; c) Alat Pemberi Isyarat Lalu Lintas; d) Alat penerangan jalan; e) Alat pengendali dan pengaman pengguna jalan; f) Alat pengawasan dan pengamanan jalan; g) Fasilitas untuk sepeda, pejalan kaki, dan penyandang cacat; dan; h)Fasilitas pendukung kegiatan lalu lintas dan angkutan jalan yang berada di jalan dan di luar badan jalan yang meliputi: a) Trotoar; b) Lajur sepeda; c) Tempat penyeberangan pejalan kaki; d) Halte; dan/atau e) Fasilitas khusus bagi penyandang cacat dan manusia usia lanjut.

\section{Penerapan Rute Aman Selamat Sekolah}

Rute Aman Selamat Sekolah yang selanjutnya disebut sebagai RASS merupakan bagian dari kegiatan manajemen dan rekayasa lalu lintas berupa penyediaan sarana dan prasarana angkutan dengan pengendalian lalu lintas dan penggunaan jaringan jalan serta penggunaan sarana dan prasarana angkutan sungai dan danau dari lokasi permukiman menuju sekolah.Dalam Pedoman Teknis Program Rute Aman Selamat Sekolah Kementerian Perhubungan Satuan Kerja Direktorat Keselamatan Transportasi Darat, RASS merupakan program untuk mendorong murid dan orang tua murid untuk lebih memilih berjalan kaki bersepeda atau menggunakan angkutan umum sebagai pilihan moda yang selamat, aman, nyaman dan menyenangkan untuk berangkat dan pulang sekolah dari kawasan sekitar pemukiman sampai dengan sekolah (Wahyuni \& Nur, 2021).

RASS bertujuan untuk mengurangi jumlah kecelakaan lalu lintas yang melibatkan pelajar, mengurangi konsumsi bahan bakar, dan secara tidak langsung mengurangi kemacetan. RASS sebagaimana dijelaskan dalam Peraturan Menteri Nomor 16 Tahun 2016 diwujudkan dengan adanya fasilitas perlengkapan jalan yang terdiri atas rambu lalu lintas, marka jalan, APILL, fasilitas pejalan kaki, dan jalur khusus sepeda, halte, fasilitas parkir untuk sepeda, ruang henti 
pesepeda, alat penerangan jalan, dan/atau fasilitas khusus bagi penyandang disabiliatas (Widowati et al.,2020).

Adapun penentuan Jumlah minimal sekolah dalam 1 kawasan RASS adalah 3 sekolah dengan jumlah pelajar minimal dalam 1 sekolah adalah 300 pelajar yang berdekatan dan memunkinkan dijadikan 1 cluster. Sesuai dengan tujuan adanya RASS yaitu mengurangi kemacetan maka penetapan kawasan rass bisa menjadi bagian dari sebuah kebijakan push and pull . Salah satu upaya untuk mengurai kemacetan Kota yaitu melalui kebijakan push and pull policy. Kementerian Perhubungan Republik Indonesia, (2011) menyatakan bahwa untuk membenahi transportasi perkotaan, salah satu cara yang dilakukan pemerintah melalui kebijakan push and pull policy, membuat daya tarik (pull policy).Pullitu daya tarik dari angkutan umum agar mampu menarik mereka yang memakai kendaraan pribadi untuk menggunakan kendaraan umum (Talu \& De Gomes, 2019). Sedangkanpush policyadalah bagaimana caranya mereka yang menggunakan kendaraan itu benarbenar merasakan kendaraan pribadi ini membayar sesuai dengan apa yang dilakukan. Dalam hal ini RASS menyediakan fasilitas-fasilitas bagi siswa/i ataupun secara tidak langsung kepada masyarakat untuk bertransportasi selain kendaraan bermotor dengan lebih aman dan nyaman.

\section{Angkutan Sekolah}

Angkutan sekolah terdiri dari angkutan antar jemput anak sekolah dan angkutan kota/kabupaten anak sekolah. Angkutan antar jemput anak sekolah adalah angkutan yang khusus melayani pelajar sekolah dengan asal dan/atau tujuan perjalanan tetap, dari dan ke sekolah yang bersangkutan, diselenggarakan oleh lembaga pendidikan (Iswantono \& Kadembo, 2021).

Analisis titik lokasi halte, Halte harus direncanakan dengan baik serta terintegrasi dengan guna lahan di sekitarnya, gampang dicapai oleh penumpang termasuk oleh penderita cacat. Perhentian bus adalah lokasi dimana penumpang dapat naik dan turun dari bus, dan juga lokasi dimana bus dapat berhenti untuk menaikkan dan menurunkan penumpang sesuai dengan pengaturan operasional ataupun permintaan penumpang. Jadi, pada dasarnya perhentian bus adalah titik-titik sepanjang lintasan rute dimana pengemudi naik atau turun dari bus. Secara fisik, perhentian bus dapat dilengkapi dengan prasarana berupa shelter atau juga hanya berupa rambu. Suatu lintasan rute biasanya dilengkapi dengan sekumpulan titik perhentian dimana bus dapat berhenti untuk menaikkan dan menurunkan penumpang. Tetapi meskipun suatu lintasan telah dilengkapi dengan sekumpulan titik perhentian, belum tentu secara operasional bus akan selalu berhenti di titik-titik perhentian tersebut, karena itu sangat tergantung pada kebijakan operasional dari pengelola. Jarak berjalan kaki adalah jarak dari tempat calon penumpang ke perhentian bus. Sedangkan jarak yang masih diterima penumpang adalah jarak yang masih dianggap nyaman bagi calon penumpang untuk berjalan dari tempat tinggal ke perhentian bus terdekat.

Perhitungan jumlah kebutuhan, Perencanaan pengoperasian angkutan tidak dapat dipisahkan dari penyediaan prasarana yang tepat dan sesuai kebutuhan. Hal tersebut diperlukan agar kegiatan pengoperasian angkutan dapat berjalan sesuai dengan rencana. Untuk perencanaan pengoperasian 
angkutan sekolah pada sekolah yang berada dikawasan pendidikan Kota Balikpapan ini, penentuan kebutuhan halte berdasarkan kepada jarak antar halte yang dibutuhkan.

Dalam desain halte yang aman dan ideal, keberadaan halte untuk rencana pengoperasian bus memiliki fungsi utama sebagai tempat menaikkan dan menurunkan pelajar. Halte adalah tempat perhentian kendaraan penumpang umum untuk menurunkan dan/atau menaikkan penumpang yang dilengkapi dengan bangunan. Sementara tempat perhentian bus (bus stop) adalah titik untuk menurunkan dan/atau menaikkan penumpang tanpa dilengkapi bangunan, hanya diberi fasilitas rambu. Secara umum perhentian angkutan sekolah dapat dikelompokkan menjadi empat kategori: a) Perhentian angkutan di ujung rute atau terminal, dimana angkutan harus mengakhiri perjalanannya ataupun memutar untuk memulai perjalanannya lagi. Pada lokasi perhentian ini penumpang harus mengakhiri perjalanannya atau penumpang dapat mengawali perjalanannya; $b$ ) Perhentian angkutan yang terletak disepanjang lintasan rute, perhentian ini harus disediakan dengan jarak dan jumlah yang memadai, agar penumpang dimudahkan untuk akses dan juga agar kecepatan angkutan dapat dijaga pada batas yang wajar; c) Perhentian angkutan titik dimana dua atau lebih lintasan rute bertemu (Azis, 2018). Pada perhentian ini penumpang dapat bertukar angkutan (transfer) dengan lintasan rute lainnya. Untuk beberapa kasus tertentu, angkutan diatur jadwalnya agar pada saat mencapai titik transfer ini pada waktu yang bersamaan, sehingga penumpang yang ingi transfer tidak perlu menunggu; dan d) Perhentian angkutan pada intermodal terminal, dimana penumpang dapat bertukar moda. Pada perhentian jenis ini pengaturan dan perencanaan yang baik sangatlah dibutuhkan agar intermodality dapat terjadi secara efisien dan efektif.

\section{METODE}

Penelitian ini menggunakan jenis penelitian kualitatif dengan pendekatan analisis deskriptif. Data dalam penelitian ini berjenis data primer dan data sekunder. Pada kajian ini peneliti mengambil populasi masing-masing dari 4 sekolah di kawasan pendidikan. Dalam mengambil sampel peneliti menggunakan rumus Slovin dengan tingkat kepercayaan 90\%. Teknis analisis data

yaitu dengan menentukan kawasan RASS, mengidentifikasi perjalanan dari dan ke sekolah yang terdiri dari rute pejalan kaki dan rute pesepeda, menganalisis kebutuhan perjalanan dari dan ke sekolah yang terdiri dari kebutuhan pejalan kaki, kebutuhan fasilitas penyebrangan, dan Zona Selamat Sekolah sehingga dapat diambil sebuah kesimpulan dan dampak dari penerimaan RASS.

\section{HASIL DAN PEMBAHASAN}

\section{Identifikasi Asal dan Tujuan Siswa}

Dalam menentukan asal dan tujuan siswa/I, didapatkan dari data alamat siswa/I, dimana alamat ini merupakan asal siswa melakukan perjalanan dengan tujuan pada zona kawasan sekolah. Adapun beberapa tahapan yang dilakukan yaitu menentukan kawasan rute aman selamat sekolah.

Berdasarkan PM 16 Tahun 2016 tentang rute Aman Selamat Sekolah, Penentuan kawasan ini juga tidak lepas dari batas radius dimana untuk pejalan kaki paling jauh $1 \mathrm{KM}$, kemudian untuk 
pengguna Sepeda yaitu paling jauh $5 \mathrm{KM}$ dan terakhir untuk angkutan umum yaitu diatas $5 \mathrm{KM}$ penentuan kawasan RASS adalah sebagai berikut: a) Titik sekolah berada pada kawasan pendidikan yang terletak di jalan KP Tendean kelurahan Telagasari; b) Pada kawasan tersebu terdapat 4 sekolah yang saling berdekatan (dengan jarak kurang dari 100 meter) dan memiliki jummlah siswa masing masing diatas 300 siswa (yang dapat dilihat di tabel V.1) sehingga dapat dikategorikan sebagai kawasan pendidikan; c) Adapun pemukiman yang berdekatan dengan kawasan pendidikan ini yang merupakan tempat tinggal mayoritas siswa/I yang sekolahnya berada pada kawasan pendidikan ini salah satu contohnya perumahan Telagasari.

Tabel 1. Lokasi penelitian

\begin{tabular}{|c|c|c|c|c|}
\hline No. & Nama Sekolah & Jumlah Siswa & Lokasi & Jam oprasional \\
\hline 1. & $\begin{array}{c}\text { SDN 001 Balikpapan } \\
\text { Kota }\end{array}$ & 777 Siswa & Jl. KP. Tendean & $07.00-13.00$ \\
\hline 2. & SMPN 12 Balikpapan & 1072 Siswa & Jl. KP. Tendean & $07.00-15.00$ \\
\hline 3. & SMPN 1 Balikpapan & 1060 Siswa & J1. KP. Tendean & $07.00-15.00$ \\
\hline 4. & SMAN 1 Balikpapan & 1234 Siswa & Jl. KP. Tendean & $07.00-16.00$ \\
\hline
\end{tabular}

Sumber: data diolah

Berdasarkan kriteria penentuan kawasan RASS maka peneliti menggunakan empat sekolah untuk dijadikan objek penelitian, yaitu SDN 001 Balikpapan Kota, SMPN 12 Balikpapan, SMPN 1 Balikpapan, dan SMAN 1 Balikpapan yang letaknya berdekatan pada J1. KP. Tendean dengan jam oprasional sekolah berkisar antara pukul 07.00-16.00, sehingga cocok untuk dijadikan satu cluster sebagai kawasan RASS.

\section{Moda yang Digunakan Pelajar}

Jenis moda yang digunakan pelajar dalam melakukan perjalanan menuju tempat sekolah dapat dilihat pada gambar berikut:

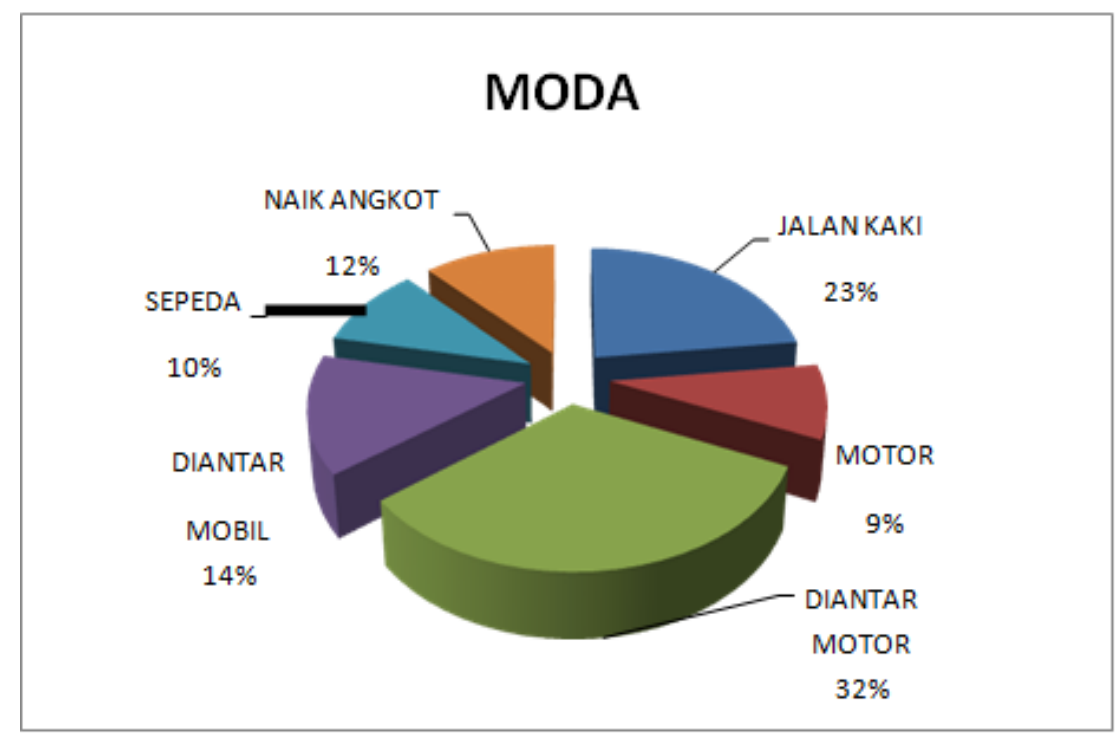

Gambar 1. Persentase pemilihan moda siswa dan siswi

Berdasarkan Gambar 1 diketahui bahwa presentase moda yang digunakan pelajar dalam menempuh perjalanan ke sekolah paling banyak adalah diantar menggunakan sepeda motor, yaitu 
sebesar 32\%. Hal ini dikarenakan orangtua memilih moda yang simple sehingga setelah mengantarkan anak kesekolah dapat melanjutkan perjalanan yang lain contohnya tempat kerja. Lokasi sekolah yang dekat pemukiman juga menyebabkan pada tingginya pelajar yang berjalan kaki yang cukup tinggi sebanyak 965 pelajar atau sekitar $23 \%$ dan bersepeda menuju sekolah sebanyak 10\%. Untuk mengetahui lebih rinci pemilihan moda ditiap sekolah, dapat dilihat dalam Tabel berikut:

Tabel 2. Persentase penggunaan mode tiap sekolah

\begin{tabular}{|c|c|c|c|c|c|}
\hline \multicolumn{7}{|c|}{ MODA } \\
\hline MODA & SDN 001 & SMPN 1 & SMPN 12 & SMAN 1 & TOTAL \\
\hline Jalan Kaki & 259 & 239 & 308 & 158 & 965 \\
\hline Motor & 0 & 0 & 0 & 362 & 363 \\
\hline Diantar Motor & 563 & 1003 & 775 & 362 & 2701 \\
\hline Diantar Mobil & 158 & 296 & 228 & 453 & 1135 \\
\hline Sepeda & 90 & 68 & 148 & 102 & 409 \\
\hline Naik Angkot & 68 & 114 & 103 & 204 & 488 \\
\hline Jumlah & 1137 & 1721 & 1562 & 1641 & 6062 \\
\hline
\end{tabular}

Sumber: data diolah

Dari Tabel 2 dapat diketahui penggunaan moda pada tiap sekolah. penggunaan moda diantar menggunakan sepeda motor tertinggi pada SMPN 1 Balikpapan sebesar 1003 orang. penggunaan moda diantar menggunakan mobil tertinggi pada SMAN 1 Balikpapan sebesar 453 orang. penggunaan moda sepeda tertinggi pada SMPN 12 Balikpapan sebesar 148 orang. pejalan kaki menuju sekolah tertinggi pada SMPN 12 Balikpapan sebesar 308 orang. pengguna angkutan umum tertinggi pada SMAN 1 Balikpapan sebesar 204 orang. Sedangkan pada moda motor terdapat pada SMAN 1 Balikpapan sebesar 362 orang pengguna motor memang hanya pada siswa/I SMA dikarenakan usia mereka sudah cukup untuk memiliki SIM agar mengendarai motor mereka sendiri.

\section{Penentuan Rute Pejalan Kaki}

Dalam Peraturan Menteri Perhubungan PM 16 Tahun 2016 dijelaskan bahwa RASS dengan kriteria pelayanan berjalan kaki merupakan rute dari rumah menuju ke sekolah dengan menggunakan moda berjalan kaki dengan radius paling jauh $1 \mathrm{Km}$ dari lokasi sekolah yang disimbolkan dengan jalan berwarna biru seperti dijelaskan pada Gambar berikut: 


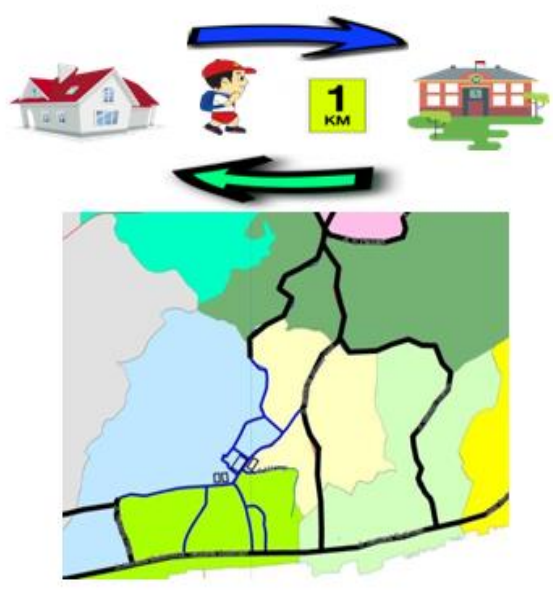

Gambar 2. Ilustrasi Skema RASS untuk pejalan kaki

Dalam pedoman RASS dijelaskan bahwa pelayanan berjalan kaki merupakan rute dari rumah menuju ke sekolah dengan berjalan kaki dengan radius paling jauh $1 \mathrm{~km}$ dari lokasi sekolah. Maka dari titik kawasan RASS sudah dapat ditentukan seberapa jauh rute berjalan kaki.

\section{Penentuan Rute Pesepeda}

Jalur khusus sepeda dalam Peraturan Menteri No 16 Tahun 2016 Tentang Rute Aman Selamat Sekolah (RASS) merupakan lajur sepeda yang disediakan secara khusus untuk pesepeda dan/atau dapat digunakan bersama-sama pejalan kaki. Dalam Peraturan Menteri tersebut juga dijelaskan bahwa RASS dengan kriteria pelayanan bersepeda merupakan rute dari rumah menuju ke sekolah dengan menggunakan sepeda dengan radius paling jauh $5 \mathrm{~km}$ dari lokasi sekolah.

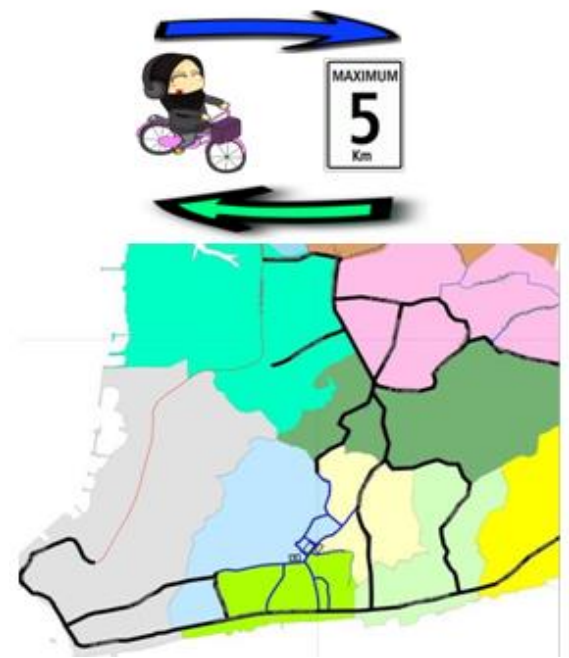

Gambar 3. Skema RASS dengan Pesepeda

Sumber: data diolah 
Berikut ini merupakan ruas-ruas jalan di sekitar kawasan RASS yang menjadi lokasi penelitian dengan jarak dibawah radius $5 \mathrm{~km}$ diukur dari lokasi sekolah. Zona pengguna moda sepeda berada pada 7 zona yaitu klandasan ulu, klandasan ilir, Telagasari, gunung sari ilir, Gunung sari Ulu, Damai, dan Prapatan. Dari data tersebut diasumsikan bahwasanya Siswa (responden) mengunakan ruas-ruas jalan yang melayani zona asal siswa/I sebagai rute dari rumah mereka ke sekolah, berikut tabel ruas jalan yang digunakan siswa/I dari rumah ke sekolah. Dalam menentukan rute pesepeda, tentunya tidak semua jalan akan dijadikan rute dan diberikan fasilitas sepeda, ada beberapa kriteria diantaranya yaitu jika volume sepeda lebih dari 200 per 12 jam maka ruas jalan tersebut harus diberikan fasilitas jalur sepeda. Berikut tabel volume sepeda tiap ruasnya

Volume pesepeda di beberapa jalan tergolong kecil (intesitas rendah), yaitu Jalan Wilyopuspoyudo, Jalan Brigjen Erry Supardjan, Jalan Milino, Jalan Telagasari dalam, Jalan Mayjend Sutoyo, Jalan Letjend S. Parman, dan Jalan MP. Zainal Arifin. Berdasarkan Land Transport Safety Authority (2004), rute sepeda direcanakan perlu memperhatikan Beberapa Hal salah satunya yaitu Directness, dimana Rute sepeda sebaiknya langsung membawa pesepeda menuju ke tempat tujuan mereka yang berada di sepanjang jalur sepeda. Berikut rekomendasi Rute Pesepeda.

\section{Penentuan Rute Angkutan Umum}

Dalam Peraturan Menteri Perhubungan PM 16 Tahun 2016 dijelaskan bahwa RASS dengan kriteria pelayanan angkutan umum merupakan rute dari rumah menuju ke sekolah dengan menggunakan angkutan umum dengan radius $5 \mathrm{~km}$ dari lokasi sekolah, dan jarak dari rumah ke tempat pemberhentian angkutan umum maksimal 1 kilometer sebagaimana dijelaskan pada Gambar berikut:

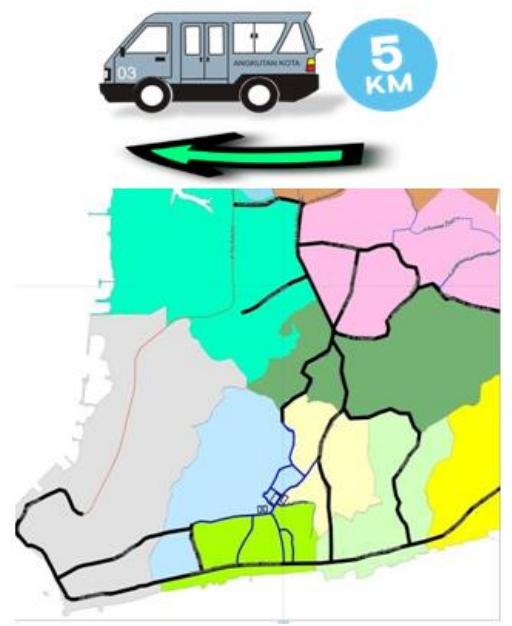

Gambar 4. Skema RASS untuk Pengguna Angkutan Umum

Pada penelitian ini, penentuan rute menggunakan rute angkutan umum eksisting di Kota Balikpapan yang akan diidentifikasi berdasarkan rute yang dilewati seperti Pada Tabel 3, apakah sudah melayani zona asal siswa pada daerah penelitian.

Tabel 3. Inventarisasi Rute Angkutan Umum kota Balikpapan 


\begin{tabular}{|c|c|c|c|}
\hline No. & Trayek & Rute & Keterangan \\
\hline 1 & 1 & RSS Damai III-Kampung Baru PP & Beroperasi \\
\hline 2 & 2 & Terminal Batu Ampar-Balikpapan Baru PP & Tidak Beroperasi \\
\hline 3 & $2 \mathrm{~A}$ & Terminal Damai-Terminal Batu Ampar PP & Beroperasi \\
\hline 4 & 3 & Terminal Batu Ampar-Pelabuhan PP & Beroperasi \\
\hline 5 & 4 & Pelabuhan-Terminal Batu Ampar PP & Tidak Beroperasi \\
\hline 6 & 5 & Kampung Baru-Terminal Damai PP & Beroperasi \\
\hline 7 & 6 & Pelabuhan KP. Baru- Terminal Damai PP & Beroperasi \\
\hline 8 & 7 & Terminal Damai-Gunung Tembak PP & Beroperasi \\
\hline 9 & 8 & Terminal Batu Ampar-KM. 24 PP & Beroperasi \\
\hline 10 & $8 \mathrm{~A}$ & Terminal Batu Ampar-Kariangau PP & Tidak Beroperasi \\
\hline 11 & 9 & KP. Baru-Terminal Batu Ampar PP & Beroperasi \\
\hline
\end{tabular}

\section{Sumber: data diolah}

Berdasarkan data pada tabel di atas,d apat diketahui bahwa: 1) Trayek 1, RSS Damai IIITerminal Batu Ampar-Karang Anyar-Kampung Baru PP. Melayani: Somber,Inpres IV, Gunung Pipa, Gunung IV, Asrama Bukit, Kebun Sayur; 2) Trayek 2A, Terminal Damai-Jl. MT. HaryonoPerum. Bpp Baru/RSS Damai III- RSS Damai Beriman/Kopri-Terminal Batu Ampar PP. Melayani: SMUN 4, Ps. Sepinggan, Komp. Prajja Bakti/Pemda, Perum. Taman Sari, Bukit Mutiara, Sumber Rejo, Gunung Guntur; 3) Trayek 3, Terminal Batu Ampar-Rapak-Gunung SariKlandasan-Pelabuhan PP. Melayani: Somber, Gn. Samarinda, sumber Rejo, Karang Rejo,Karang Jati, Jl. P. Antasari, Jl. S. Parman, Martadinata, Jl. Kapten. Piere Tendean, Sentosa,Prapatan; 4) Trayek 5, Kampung Baru-Kebun Sayur-Karang Anyar-Rapak-Gunung Sari- Pasar Baru-Terminal Damai PP. Melayani: Gunung Empat, Gunung Pipa, Karang Rejo,JL. P Antasari,JL. S. Parman. JL. Mayjend Sutoyo; 5) Trayek 6, Kampung Baru- Karang Anyar-Pelabuhan-Klandasan-Terminal Damai PP. Melayani: JL. Kapten Piere Tendean, JL. A. Fadhilah,Gunung Sari, Antasari, Pasar Baru; 6) Trayek 7, Terminal Damai-Sepinggan-Batakan-Manggar-Gunung Tembak PP. Melayani: Pasar Sepingan dan Perum. Sosial; 7) Trayek 8, Terminal Batu Ampar-KM. 24 PP ; dan 8) Trayek 9, KP. Baru-Jumpi-Somber-Terminal Batu Ampar PP .

\section{Penyediaan Fasilitas}

Setelah Melakukan identifikasi Rute pada tiap-tiap modanya, selanjutnya yaitu melaukan analisis penyediaan fasilitas untuk menunjang keamanan, kenyamanan, dan keselamatan khususnya para siswa/I di kawasan pendidikan tersebut, berikut analisis fasilitas diantaranya adalah fasilitas pejalan kaki yaitu trotoar.

Dalam pedoman teknis RASS, trotoar merupakan jalur pejalan kaki yang terletak di ruang manfaat jalan, diberi lapis permukaan, diberi elevasi lebih tinggi dari permukaan perkerasan jalan, ditempatkan dipinggir sejajar jalur lalu lintas kendaraan. Sementara untuk standar teknis trotoar meliputi: a) Penempatan trotoar seharusnya lebih tinggi dari perkerasan jalan; b) Penempatan trotoar seharusnya diletakan pada sisi bahu luar jalan; c) Trotoar dapat ditempatkan pada sisi dalam drainase terbuka atau diatas saluran drainase yang sudah ditutup dengan plat beton; d) Trotoar 
pada pemberhentian atau halte dapat ditempatkan dibelakang trotoar halte; e) Permukaan trotoar harus dibedakan dengan warna jalan dan dapat memiliki desain yang menarik; f) Trotoar seharusnya memiliki ruang bebas, minimal setinggi 2,5 meter; dan g) Lebar trotoar RASS seharusnya berkisar antara 1,4 - 2,5 meter, untuk kapasitas 2 (dua) orang sehingga dapat berjalan dengan nyaman.

Selain itu, fasilitas penyebrangan terdiri dari: a) Zebra Cross: Zebra Cross tanpa perlindungan dan Zebra Cross dengan perlindungan, b) Pelican Crossing terdiri dari Pelikan tanpa perlindungan dan Pelikan dengan perlindungan; dan 3) Penyeberangan Tidak Sebidang terdiri dari Jembatan danTerowongan.

Selanjutnya, Zona Selamat Sekolah ZoSS merupakan bagian dari kegiatan manajemen dan rekayasa lalu lintas berupa pengendalian lalu lintas dan penggunaan suatu ruas jalan di lingkungan sekolah. ZoSS bertujuan untuk mencegah terjadinya kecelakaan guna menjamin keselamatan anak di sekolah (Keputusan Direktur Jenderal Perhubungan Darat Nomor:

SK.3582/AJ.403/DJPD/2018 tentang Pedoman Teknis Pemberian Keselamatan dan Kenyamanan Pejalan Kaki Pada Kawasan Sekolah Melalui Penyediaan Zona Selamat Sekolah, ZoSS ditetapkan berdasarkan: a) Jumlah paling banyak 2 lajur per jalur; dan b) Tidak tersedia jembatan penyeberangan orang.

Berdasarkan kriteria diatas, maka pada lokasi penelitian perlu diterapkan ZoSS. Teknis penerapan ZoSS berdasarkan Keputusan Direktur Jenderal Perhubungan Darat Nomor: SK.3582/ AJ.403 / DJPD /2018 tentang ZoSS, dan berdasarkan kondisi eksisting wilayah penelitian, maka ZoSS yang akan diterapkan adalah tipe ZoSS dengan sekolah dekat dengan Persimpangan, yang visualisasinya dapat dilihat pada Gambar berikut:

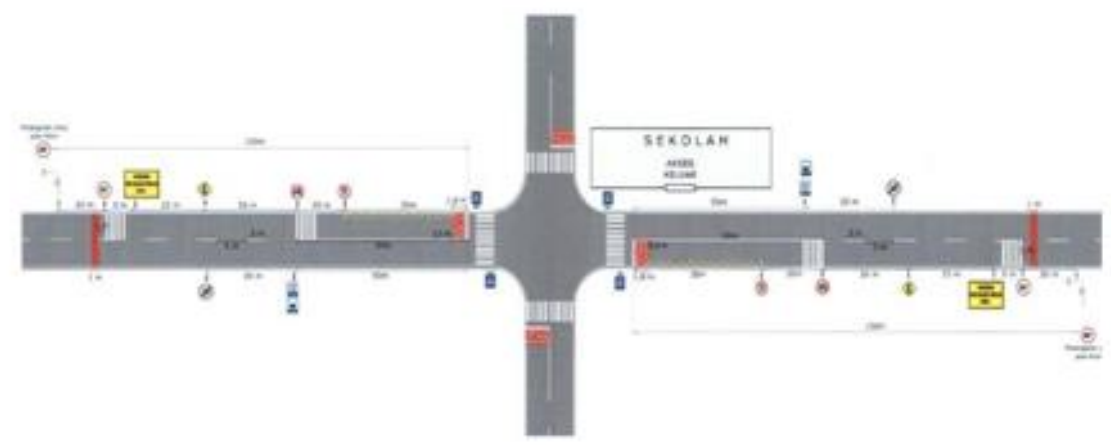

Gambar 5. Desain ZoSS pada Lokasi Persimpangan

Sedangkan untuk penentuan fasilitas pesepeda, ada beberapa hal hal yang perlu diperhatikan khususnya penyesuaiian dengan kondisi eksisting wilayah kajian. Berikut beberapa analisis penyedian fasilitas pesepeda: Pertama, yaitu Lajur Sepeda Jalur/lajur sepeda merupakan jalur/lajur yang digunakan khusus untuk pesepeda. Standar teknis jalur/lajur sepeda antara lain meliputi: 1) Ukuran lebar jalur sepeda sampai dengan $2 \mathrm{~m}$; 2) Menggunakan jalan paling pinggir sebelum trotoar; 3) Didesain dengan warna cerah dan menarik; merah, hijau dan biru; dan 4) Didesain garis putih memanjang sepanjang jalan.Dalam penentuan jalur/lajur sepeda, hal pertama yang kita 
lakukan adalah mengidentifikasi spesifikasi sepeda yang sering digunakan pelajar di daerah studi. Sepeda yang biasa dipakai oleh pelajar dalam penentuan rute ini adalah jenis sepeda standar dengan ukuran rata-rata $65 \mathrm{~cm}$.

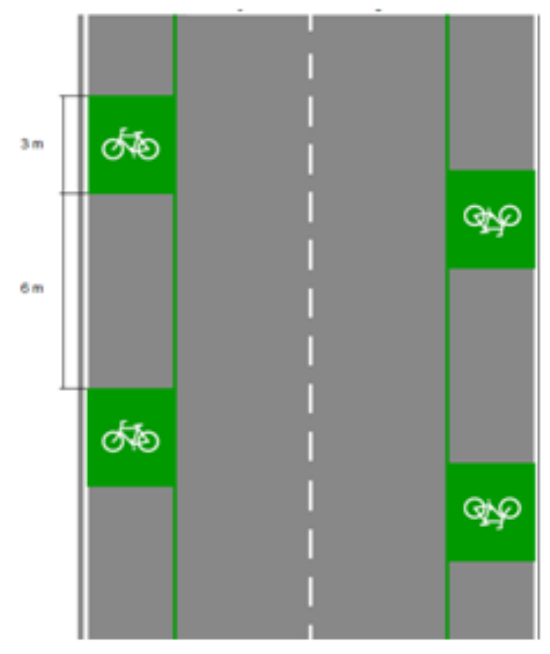

Gambar 6. Marka Jalur Sepeda

Untuk ruang yang di butuhkan sepeda (satu arah) adalah lebar 100-120 cm serta tinggi ruang setidaknya $200 \mathrm{~cm}$. Sementara ruang yang dibutuhkan sepeda untuk dua arah adalah lebar minimal $200 \mathrm{~cm}$. Kecepatan rata-rata sepeda pada jalan raya ialah 10-20 km/jam. Untuk jalan dengan lajur sepeda pada 1 jalur akan diberikan marka dan rambu pembatasan kecepatan serta peringatan banyak pesepeda pada ruas jalan tersebut untuk menambah aspek keselamatan bagi pengguna sepeda. Setelah mengetahui jalan mana saja yang akan dijadikan jalur/lajur sepeda, maka langkah selanjutnya menentukan jenis jalur/lajur. Diketahui fasilitas bagi pesepeda di perkotaan dibagi menjadi 3 tipe yaitu jalur sepeda di badan jalan (Tipe A), lajur sepeda di trotoar (Tipe B), dan lajur sepeda di badan jalan (Tipe C) dengan mempertimbangkan keamanan, keselamatan, ketertiban, dan kelancaran dalam berlalu lintas.

Kedua, yaitu Ruang Tunggu atau Henti Sepeda. Ruang henti atau tunggu untuk sepeda merupakan sebuah ruangan dibagian ujung paling depan di suatu lengan simpang yang digunakan untuk antri menyeberang dengan menggunakan sepeda. Standar teknis ruang tunggu bersepeda antara lain meliputi: a) Ukuran ruang tunggu 4 x $1.2 \mathrm{~m}$; b) Menggunakan pembatas garis orange sebagai pembatas antri untuk menyeberang; dan c) Didesain dengan warna cerah dan menarik; dan d) Didesain di belakang tempat penyeberangan sejajar trotoar. Selain ruang tunggu sepeda, pada persimpangan juga dilengkapi dengan marka khusus penyeberangan untuk pesepeda.

Ketiga, Fasilitas Parkir Sepeda. Penyediaan tempat parkir sepeda juga menjadi salah satu fasilitas yang diinginkan Siswa/I dimana fasilitas ini menambah rasa aman dan nyaman pada saat siswa/I meninggalkan sepedanya untuk proses belajar di dalam kelas, berikut contoh fasilitas parkir yang dapat disiapkan di sekolah.

Untuk Penentuan Fasilitas Angkutan Umum, Penyediaan prasarana yang tepat akan menunjang pengoperasian angkutan yang telah ada, penentuan kebutuhan halte berdasarkan kepada jarak antar halte yang dibutuhkan sesuai dengan Keputusan Direktur Jenderal Perhubungan 
Darat Nomor 271 Tahun 1996 tentang Pedoman Teknis Perekayasaan Tempat Perhentian Kendaraan Penumpang Umum.

Sedangkan persyaratan umum tempat perhentian kendaraan penumpang umum dalam Keputusan Direktur Jenderal Perhubungan Darat Nomor 271 Tahun 1996 Tentang Pedoman Teknis Perekayasaan Tempat Pemberhentian Kendaraan Penumpang Umum adalah: a) Berada di sepanjang rute angkutan umum/bus; b) Terletak pada jalur pejalan (kaki) dan dekat dengan fasilitas pejalan (kaki); c) Diarahkan dekat dengan pusat kegiatan atau permukiman; d) Dilengkapi dengan rambu petunjuk; dan d) Tidak mengganggu kelancaran arus lalu-lintas. Berdasarkan Kondisi eksisting hanya terdapat rambu petunjuk halte, hal ini merupakan program dari Dinas Perhubungan Kota Balikpapan yang telah menentukan lokasi halte di kawasan pendidikan tersebut tetapi masih belum membangun dan mendesain halte angkutan umum sesuai dengan dengan Peraturan Menteri Perhubungan No. 16 Tahun 2016 tentang Rute Aman Selamat Sekolah dimana halte yang berkeselamatan sesuai dengan Peraturan Menteri Nomor 16 tahun 2016 tentang Rute Aman Selamat Sekolah.

\section{E. KESIMPULAN}

Kesimpulan yang dapat diambil dari hasil penelitian tentang Penerapan Konsep Rute Aman Selamat Sekolah (RASS) Di Kawasan Pendidikan Kota Balikpapan sebagai berikut: 1) Kawasan Rute Aman Selamat Sekolah (RASS) mencakup 4 sekolah yaitu SD 001 Balikpapan, SMPN 12 Balikpapan, SMPN 1 Balikpapan, SMAN 1 Balikpapan; 2) Fasilitas rute pejalan kaki dan desainnya mencakup lebar trotoar pada jalan KP Tendean, jalan Wilyopuspoyudho, Jalam Arsh. Moh, Jalan Milino, Jalan Brigjen Ery Supardjan, Jalan Tanjung Pura, Jalan Telagasari, Jalan Telagasari Dalam, Jalan RE Martadinata. Adapun fasilitas penyebrangan terdapat pada Jalan KP Tendean; 3) Fasilitas angkutan umum mencakup mendesain halte untuk lokasi eksisting, dikarenakan belum adanya halted an hanya penambatan rambu bus stop; dan 4) Fasilitas drop zone/pick up point diterapkan agar memberikan rasa aman bagi siswa yang diantar jemput dan tidak mengganggu aktivitas lau lintas sekitar.

\section{DAFTAR PUSTAKA}

Aprizon, A. S. (2020). Penerapan Rute Aman Selamat Sekolah (Rass) Pada Ruas Jalan Jaksa Agung Soeprapto Di Kabupaten Tabalong. Penerapan Rute Aman Selamat Sekolah (Rass) Pada Ruas Jalan Jaksa Agung Soeprapto Di Kabupaten Tabalong.

Arianto, S. B., \& Heriwibowo, D. (2017). Kajian Rute Aman Selamat Sekolah (Rass) Di Kecamatan Pare Kabupaten Kediri. Jurnal Penelitian Transportasi Darat, 19(4), 247-262.

Azis, A. (2018). Karakteristik Perilaku Penyeberang dan Pengantar Pada ZoSS di Kabupaten Maros Provinsi Sulawesi Selatan. Seminar Nasional Teknik Sipil 2018.

Dedi Faturrahman, S. (2020). Penerapan Konsep Rute Aman Selamat Sekolah Di Jalan Supratman Dan Ra Kartini Kabupaten Indramayu. Penerapan Konsep Rute Aman Selamat Sekolah Di Jalan Supratman Dan Ra Kartini Kabupaten Indramayu. 
Haradongan, F. (2017). Rute Aman Selamat Sekolah (Rass) Di Kabupaten Ngawi School Safety Routes In Ngawi District. Jurnal Penelitian Transportasi Darat, 19(2), 119-132.

Hartono, H., Subaryata, S., \& Heriwibowo, D. (2020). Rute Aman Selamat Sekolah di Kabupaten Lampung Selatan. Jurnal Penelitian Transportasi Darat, 22(1), 77-90.

Heriwibowo, D. (2020). Halaman Depan Juni 2020. Jurnal Penelitian Transportasi Darat, 22(1).

Iswantono, T., \& Kadembo, E. A. M. (2020). Analisa Perilaku Happy Gowes Terhadap Marka Utuh Di Jalan Darmo Surabaya. Court Review: Jurnal Penelitian Hukum (e-ISSN: 27761916), 1(03), 35-46.

Liliany, L., Priyanto, S., \& Parikesit, D. (2019). Rute Aman Selamat Sekolah (RASS) di Kota Yogyakarta (Studi Kasus Jl. Kapten Pierre Tendean). Jurnal Penelitian Transportasi Darat, 21(1), 37-46.

Maulidya, I. (2016). Perencanaan Lokasi Jalur Sepeda Dalam Rangka Mendukung Program Rute Aman Selamat Sekolah Di Kota Kediri Provinsi Jawa Timur Bike Lanes Planning To Support School Safety Routes Program In Kediri City, East Java Province. Puslitbang Transportasi Jalan dan Perkeretaapian, Jakarta, 18(3), 219-230.

Mushoffan, A., \& Harjoto, B. (2019). Sistem Informasi Rute Aman Selamat Sekolah (SIRASS) Menggunakan Aplikasi Mobile Berbasis Android di Kota Kediri. Jurnal Penelitian Transportasi Darat, 21(1), 91-102.

Nurcahyo, B. T., \& Iskandaria, H. (2020). Penerapan Arsitektur Metafora Pada Sekolah Tinggi Transportasi Darat Di Jakarta. Maestro, 3(2), 152-162.

Prasetyo, A., Nugroho, M. W., Amudi, A., \& Yulianto, T. (2020). Kajian Awal Perencanaan Lajur Khusus Sepeda Dengan Menggunakan Metode IPA (Importance Performance Analysis) dan SWOT. Publikasi Riset Orientasi Teknik Sipil (Proteksi), 2(2), 41-47.

Talu, A. T. I., \& De Gomes, F. (2019). Identifikasi Sekolah Ramah Anak Pada Satuan Paud Di Kecamatan Langke Rembong Berdasarkan Kebijakan Pengembangan Sekolah Ramah Anak. Jurnal Pendidikan dan Kebudayaan Missio, 11(1), 147-159.

Ulandari, F. S., \& Pangaribuan, J. (2015). Perencanaan Angkutan Sekolah Guna Mewujudkan Konsep Rass (Rute Aman Selamat Sekolah) Di Kota Tanjung Selor. Jurnal Penelitian Sekolah Tinggi Transportasi Darat, 6(2), 58-66.

Wahyuni, R. E., Nashrullah, N., \& Nur, Y. A. (2021). Integrasi Infrastruktur Sepeda dan Zona Selamat Sekolah. Jurnal Manajemen Bisnis Transportasi dan Logistik, 7(1).

Widowati, E., Koesyanto, H., Sugiharto, S., Wahyuningsih, A. S., \& Harjanto, E. (2020). Model Konstruksi Safety Grievance Mechanism di Sekolah Dasar pada Daerah Rawan Bencana. HIGEIA (Journal of Public Health Research and Development), 4(4), 667-680. 